\title{
Teacher resistance to computer-assisted instruction
}

\author{
THERON STIMMEL, JAMES L. CONNOR, \\ EDWIN O. MCCASKILL, and H. JOHN DURRETT \\ Center for Automated Systems in Education, Southwest Texas State University, San Marcos, Texas 78666
}

The need to introduce computers to a greater extent in teaching technology is discussed. Further, the potential importance of affective responses in the teacher's acceptance of the computers is developed. A semantic differential scale was employed to measure preservice teachers' attitudes toward the computer, computer-aided instruction, science, mathematics, and the teaching of science and mathematics. Considerable negative affect was found toward computers, computer-aided instruction, and teaching of science and mathematics. Implications for the ways in which computer-aided instruction is introduced are discussed.

The computer is rapidly achieving recognition as a potentially powerful tool for improving education at all levels. Henderson (1978) has argued that all public school teachers and school administrators should receive extensive training in computer science. Licklider (1979) has criticized the lack of computers in public school education. A recent survey of 22 teacher training programs in the South and Southwest reveals that in neither the teacher training curriculum nor teacher education guidelines for prospective teachers is there either a requirement of, or recommendations for, course work in computer science (McCaskill, Note 1).

The Center for Automated Systems in Education at Southwest Texas State University is introducing teachers and public school administrators to the use of microcomputers as teaching devices and aids. We are doing this by using workshops and by integrating microcomputers into methods courses in science teaching. Anecdotal evidence obtained from teachers reveals a considerable amount of negative affect toward computers and computer-aided instruction. The present study is an attempt to analyze the affective attitudes of teachers toward the computer and computer-aided instruction.

Connor (1972) has argued that the use of conventional questionnaires and requests for opinions from teachers or education students on teaching-related matters should be rejected. It was argued that such requested introspections would be influenced by the fact that education students and teachers might feel they should have certain attitudes toward teaching and teaching-related topics. Since some of the topics in the present study might be considered those to which

This research was supported by an Information Dissemination in Science Education Grant SER80-09114 from the National Science Foundation, Edwin O. McCaskill, principal investigator. Requests for reprints should be sent to Theron Stimmel, Center for Automated Systems in Education, Southwest Texas State University, San Marcos, Texas 78666.
Table 1

Item Correlations With the Three Principal Factors in the "Computer" Semantic Differential

\begin{tabular}{|c|c|c|c|}
\hline & Item & & Correlation \\
\hline \multicolumn{4}{|c|}{ Oppressiveness (53.0\%) } \\
\hline Alive & $1-5$ & Dead & .70 \\
\hline Happy & $1-5$ & Sad & .71 \\
\hline Dirty & $1-5$ & Clean & -.22 \\
\hline Dark & $1-5$ & Light & -.28 \\
\hline Open & $1-5$ & Closed & .36 \\
\hline Empty & $1-5$ & Full & -.26 \\
\hline Fresh & $1-5$ & Stale & .42 \\
\hline Bitter & $1-5$ & Sweet & -.25 \\
\hline Beautiful & $1-5$ & Ugly & .51 \\
\hline $\operatorname{Dim}$ & $1-5$ & Bright & -.31 \\
\hline \multicolumn{4}{|c|}{ Remoteness (21.7\%) } \\
\hline Happy & $1-5$ & Sad & .33 \\
\hline Dirty & $1-5$ & Clean & -.22 \\
\hline Dark & $1-5$ & Light & -.53 \\
\hline Near & $1-5$ & Far & .40 \\
\hline Brisk & $1-5$ & Sluggish & .33 \\
\hline Open & $1-5$ & Closed & .39 \\
\hline Empty & $1-5$ & Full & -.52 \\
\hline Fresh & $1-5$ & Stale & .50 \\
\hline Bitter & $1-5$ & Sweet & -.35 \\
\hline Fast & $1-5$ & Slow & .76 \\
\hline Dull & $1-5$ & Sharp & -.56 \\
\hline Rough & $1-5$ & Smooth & -.40 \\
\hline Dim & $1-5$ & Bright & -.75 \\
\hline \multicolumn{4}{|c|}{ Potency $(10.0 \%)$} \\
\hline Heavy & $1-5$ & Light & -.57 \\
\hline Large & $1-5$ & Small & -.41 \\
\hline Narrow & $1-5$ & Wide & .56 \\
\hline Near & $1-5$ & Far & .23 \\
\hline Hard & $1-5$ & Soft & -.66 \\
\hline Bitter & $1-5$ & Sweet & -.20 \\
\hline Short & $1-5$ & Long & .27 \\
\hline Tender & $1-5$ & Tough & .54 \\
\hline Thick & $1-5$ & Thin & -.53 \\
\hline Beau tiful & $1-5$ & Ugly & .31 \\
\hline L.oose & $1-5$ & Tight & .20 \\
\hline Happy & $1-5$ & Sad & .25 \\
\hline
\end{tabular}

Note-Numbers in parentheses represent the percentage of variance accounted for. 
negative reactions might seem improper, a more indirect measure of affect was desirable.

To avoid the potential invalidity associated with requested introspection, the semantic differential technique was employed (Osgood, Suci, \& Tannenbaum, 1958). The semantic differential consists of a concept or topic with a set of bipolar adjectives. The direction and intensity of the response is indicated on a multistep scale (1-5 in the present study). The present study investigated the attitudes toward computers and computeraided instruction of teacher trainees completing their methods course in science just prior to entering student teaching.

We felt that attitudes toward science, mathematics, teaching science, and teaching mathematics were also relevant to the "psychology" of introducing a new technology into the teaching field. Therefore, the semantic differential technique was used to measure affective responses to computers, computer-aided instruction, mathematics, science, teaching mathematics, and teaching science.

\section{METHOD}

\section{Subjects}

The subjects were 109 students representing five classes of teacher trainees taking a science teaching methods course prior to student teaching. The students were from two classes in the spring of 1980 and three classes in the fall of 1980 .

\section{Materials}

The instrument used was a semantic differential scale of 25 bipolar adjectives. The items were selected from those previously used by Connor (1972). The items were selected to represent a wide range of factor-analytic diversities, including those found in attitude studies in educational research.

\section{Procedure}

The semantic differential was administered at the beginning of a regularly scheduled class period. The following written instructions were given to each student: "Each page of this survey has a topic followed by a group of adjectives paired with their opposites. Place a mark in one of the spaces between each pair of adjectives according to your reaction to the topic".

The 49 students participating in the spring of 1980 marked their responses directly on the sheet. The 60 students participating in the fall of 1980 were asked to respond on a machinereadable answer sheet. Since no differences were observed in the means and standard deviations of the two groups, the data were pooled for analysis.

\section{RESULTS}

Each of the six scales was factor analyzed by the principal-components method with a varimax rotation. Only factors accounting for at least $10 \%$ of the total variance are reported. On all of the scales, no more than three factors were necessary to account for at least $75 \%$ of the variance. Tables 1 and 2 show how factors were interpreted for the computer and computer-aided instruction scales. Adjective pairs had to correlate at least .20 with the factor in order to be incorporated in the tables. A positive correlation means that the higher
Table 2

Item Correlations With the Three Principal Factors in the "Computer-Aided Instruction" Semantic Differential Scale

\begin{tabular}{|c|c|c|c|}
\hline \multicolumn{3}{|c|}{ Item } & Correlation \\
\hline \multicolumn{4}{|c|}{ Oppressiveness ( $40.3 \%)$} \\
\hline Alive & $1-5$ & Dead & .75 \\
\hline Happy & $1-5$ & Sad & .65 \\
\hline Hard & $1-5$ & Soft & -.30 \\
\hline Brisk & $1-5$ & Sluggish & .47 \\
\hline Open & $1-5$ & Closed & .44 \\
\hline Fresh & $1-5$ & Stale & .57 \\
\hline Tender & $1-5$ & Tough & .34 \\
\hline Dull & $1-5$ & Sharp & -.30 \\
\hline Beautiful & $1-5$ & Ugly & .71 \\
\hline Dim & $1-5$ & Bright & -.23 \\
\hline \multicolumn{4}{|c|}{ Efficacy $(18.3 \%)$} \\
\hline Dark & $1-5$ & Light & .23 \\
\hline Near & $1-5$ & Far & -.25 \\
\hline Open & $1-5$ & Closed & -.34 \\
\hline Empty & $1-5$ & Full & .33 \\
\hline Fresh & $1-5$ & Stale & -.23 \\
\hline Bitter & $1-5$ & Sweet & .64 \\
\hline Fast & $1-5$ & Slow & -.26 \\
\hline Short & $1-5$ & Long & .26 \\
\hline Thick & $1-5$ & Thin & .45 \\
\hline Dull & $1-5$ & Sharp & .66 \\
\hline Rough & $1-5$ & Smooth & .39 \\
\hline Dim & $1-5$ & Bright & .73 \\
\hline \multicolumn{4}{|c|}{ Rigor (14.6\%) } \\
\hline Dirty & $1-5$ & Clean & .23 \\
\hline Near & $1-5$ & Far & .20 \\
\hline Hard & $1-5$ & Soft & -.30 \\
\hline Bitter & $1-5$ & Sweet & -.22 \\
\hline Fast & $1-5$ & Slow & -.21 \\
\hline Short & $1-5$ & Long & .46 \\
\hline Tender & $1-5$ & Tough & .57 \\
\hline Thick & $1-5$ & Thin & -.37 \\
\hline Loose & $1-5$ & Tight & .65 \\
\hline
\end{tabular}

Note-Numbers in parentheses represent the percentage of variance accounted for.

a score is on the scale, the more it loads on the factor; the reverse is true for a negative correlation. Table 3 shows the principal factors and the percentage of total variance for which each factor accounted, for each of the six scales.

\section{DISCUSSION}

Considerable negative effect seems to appear toward computers on the scale. The oppressiveness factor loads most heavily on the dead, sad, and ugly dimension. Note that a very similar oppressiveness dimension appears on the computer-aided instruction scale. The efficacy factor on the computer-aided instruction scale is probably interpretable as a positive factor. The rigor factor may indicate that the subjects view computer-aided instruction as a rigorous teaching method. Taken together, these factors indicated that someone introducing student teachers to the computer as a teaching device needs to 
Table 3

Factors Accounting for at Least $10 \%$ of the Variance for Six Semantic Differential Scales

\begin{tabular}{llc}
\hline \multicolumn{1}{c}{ Scale } & \multicolumn{1}{c}{ Factor } & PV \\
\hline \multirow{4}{*}{ Computers } & Oppressiveness & 53.0 \\
& Remoteness & 21.7 \\
& Potency & 10.0 \\
Computer-Aided Instruction & Oppressiveness & 40.3 \\
& Efficacy & 18.3 \\
& Rigor & 14.6 \\
Science & Distastefulness & 49.0 \\
& Positiveness & 20.3 \\
Mathematics & Efficacy & 15.3 \\
& Vibrancy & 57.9 \\
Teaching Science & Remoteness & 17.5 \\
& Oppressiveness & 13.2 \\
& Remoteness & 54.3 \\
Teaching Mathematics & Vigor & 15.4 \\
& Vibrancy & 13.2 \\
& Oppressiveness & 63.9 \\
\hline
\end{tabular}

Note $-P V=$ percentage of variance accounted for.

(1) induce a more positive affect toward computers, (2) stress the facilitative aspects of computer-aided instruction, (3) stress that computer-aided instruction is not overly difficult for teachers to become involved in, and (4) build on the efficacy, potency, and rigor factors in pointing out the advantages of the medium.
A program to improve attitudes toward computers might also address the problem of attitudes toward teaching science and mathematics. Note that $63.9 \%$ of the variance toward teaching mathematics was accounted for by an oppressiveness factor similar to the one that accounted for $53.0 \%$ of the variance toward computers. Future developments will have to take into account affective responses toward the subjects of science, mathematics, and computerized instruction, as well as personal attitudes toward teaching science and mathe. matics.

\section{REFERENCE NOTE}

1. McCaskill, E. Survey of teacher training programs. Manuscript in preparation, 1980.

\section{REFERENCES}

Connor, J. L. Effects of modularized science instruction on student achievement and attitudes in inner city junior high schools. Unpublished doctoral dissertation, University of Houston, 1972. Hendenson, D. L. Educational uses of the computers: Implications for teacher/administrator training. Educational Technology, 1978, 18(8), 41.

LickLide R, J. C. R. Impact of information technology on education in science and technology. In D. K. Deringer \& A. R. Molnar (Eds.), Technology in science education the next ten years: Perspectives and recommendations. Washington, D.C: National Science Foundation, July 1979.

Osgood, C. E., Suci, G. J., \& Tannenbaum, P. H. The measurement of meaning. Urbana: University of Illinois Press, 1958. 